\title{
[Commentary] Response to the UK Government Consultation: Advancing our health: prevention in the 2020s Supporting Smokers to Quit
}

\author{
Sharon $\operatorname{Cox}^{1}$ \\ 1 University College London, University of London
}

\begin{abstract}
Response to the UK Government Consultation: Advancing our health: prevention in the 2020s. Supporting Smokers to Quit using the COM-B model.
\end{abstract}

Dr Sharon Cox, Dr Catherine Kimber, Dr Eleni Vangeli and Professor Lynne Dawkins

Centre for Addictive Behaviours Research, London South Bank University

Background

Smoking is continuing to decline in the UK but this masks considerable inequalities. Smoking is much higher in the lower occupational groups (unskilled manual workers and the unemployed (Fidler et al., 2011; Hiscock, Dobbie, \& Bauld, 2015; Kock, Shahab, West, \& Brown, 2019)and those living in social housing (Jackson et al., 2019). It is also exceptionally high among those presenting with comorbidities such as homelessness (Dawkins et al., 2019), prison populations (Ritter, Stöver, Levy, Etter, \& Elger, 2011)a mental health diagnosis or dependence on other (including illicit) substances (Cookson et al., 2014). Targeting these groups will take a coordinated and invested effort from policy makers and it is unlikely that reaching these groups and changing smoking behaviour in the long-term can be achieved within existing local authority budgets.

Importantly, a significant number of smokers report no desire to quit - a national dataset of smoking in England shows only approximately $35 \%$ want to quit and intend to stop in the next 3 months (West, Mohr, Proudfoot, \& Brown, n.d.)thus a refocus is now needed to enhance motivation and opportunity. As smoking becomes increasingly concentrated amongst those with additional needs, it is unlikely that a one-size approach to cessation will be effective, and the current framework for cessation which has had some success for many smokers now needs to change. This is especially important if we are to meet the ambitious smokefree target by 2030 set out in the green paper ( $5 \%$ smoking prevalence rate). We suggest a new evidenced based approach which promotes and assists quitting by means of: i) Education around nicotine and tobacco harm reduction through public health campaigns. ii) Increasing opportunities or access to cessation services and reduced risk nicotine products. iii) Promoting the availability of less harmful products (nicotine replacement therapies, snus, e-cigarettes) whilst reducing availability of the most harmful (cigarettes, tobacco) products.

The picture from our own research and those of other groups in the UK shows a changing trend in smoking behaviour and 
smokers themselves are presenting new challenges. Recent evidence shows that many smokers are motivated to purchase cheaper products and find alternative ways of accessing tobacco (e.g. illicit or 'under the counter' cigarettes) and the number of smokers rolling their own (RYO) cigarettes is increasing (Jackson, Shahab, West, \& Brown, 2018). Consequently, although price impacts are effective at the population level (Chaloupka, Yurekli, \& Fong, 2012), for some groups of smokers, including those who may be considered the most reluctant to quit, pricing is less effective and needs to be implemented alongside other cessation support. Furthermore, while e-cigarettes (EC) are the most effective quit aid in England (Hajek et al., 2019), many smokers are yet to try them (34\% not tried according to Action on Smoking and Health (ASH), 2019).

Here we present our proposal for quitting smoking using the current best available evidence, and frame these around the COM-B model of behaviour change (Michie, van Stralen, \& West, 2011).

\section{Proposal}

The COM-B behavior change model proposes that in order to enact behaviour change (in this case smoking cessation), the person must have the necessary Capabilities, Opportunities and Motivation to change.

Capabilities - include both the physical and psychological barriers to quitting - including effects of cigarette craving and withdrawal, knowledge and awareness of how to access and utilize support services or products and accepting competing interests.

Opportunities (to quit) - can include access to and availability of services, support and treatments but price and other policies around smoking and vaping can also influence opportunities.

Motivation (to quit) - whilst improving capabilities and opportunities can serve to enhance motivation, there are other direct measures that might increase motivation, such as providing incentives, using gain and loss-framed cigarette pack messages, and supporting development of confidence to quit via mastery of harm reduction.

Many of our recommendations (see below) would need initial funding and we endorse the APPG report recommendation of introducing a polluter pays scheme as a mechanism for gathering funds from the tobacco industry (APPG, 2019). Given that the industry globally spends around $£ 200 \mathrm{~m}$ on advertising, there is clearly scope to raise funds via this mechanism. However, other recommendations, such as encouraging a switch to reduced risk products (e.g. e-cigarettes) could be very cost effective at both macro and micro levels, as the user would incur little or no financial costs (Jackson et al., 2018)whilst making significant health gains at no extra cost to the government.

\section{Capabilities}

Improved knowledge and awareness

In order to improve capabilities, the public's knowledge and awareness of reduced harm products needs urgent and immediate attention and correction. Smokers and non-smokers alike are well aware that smoking kills; even the most deprived have knowledge of this (e.g., homeless smokers in England, (Garner \& Ratschen, 2013). Indeed, from a study of 
working-class intergenerational smokers from North East of England, many stated that because the harm from smoking was so great, quitting was perceived as pointless, as 'the damage is already done' (Thirlway, 2019).

Numerous studies have shown that people are confused about nicotine and a substantial proportion think that nicotine causes cancer (e.g. (Villanti et al., 2019; Wilson, Partos, Mcneill, \& Brose, 2019). Furthermore, the Action on Smoking and Health e-cigarette (EC) report from 2019 has shown another increase in the misperceptions of EC, with 26\% thinking that they are more or equally harmful than smoking and $27 \%$ reporting that they are not sure whether they are any less harmful (Action on Smoking and Health (ASH), 2019). We have also found from our own field work with pharmacists, GPs and third sector support staff that knowledge of EC and nicotine education per se is poor (see also, Ahmed, Preshaw, Bauld, \& Holliday, 2018). This is despite the clear evidence-based conclusions of Public Health England (PHE) and the Royal College of Physicians (RCP) that EC, while not risk free, are a far safer alternative to smoking (McNeill, Brose, Calder, Bauld, \& Robson, 2018; Royal College of Physicians \& Group, 2016).

The lack of current knowledge and perceptions amongst health professionals is particularly troublesome when we consider that up to $40 \%$ of current smokers have some other competing need (health or mental illness, housing, or another addiction). Therefore, health professionals who have frequent contact with smokers need to be fully educated and up to date on the range of alternatives to smoking and be supplied with messages that inform their patients on how to quit. This aligns with the sentiment that every opportunity must be capitalized on to improve and save lives. Therefore, whilst education on the harms of smoking have a role to play in reducing smoking rates, especially in preventing smoking, campaigns centred around increasing knowledge need to go beyond the smoking kills message.

Accepting competing interests

Unfortunately, throughout our work, and in a recent systematic review of homeless smokers (Soar, Dawkins, Robson, \& Cox, under review), we commonly hear of health professionals pushing smoking to the bottom of the list. This may be because they think that people may not be capable of quitting because of other issues, because they feel they are taking away their patients' only pleasure, or due to fears that quitting smoking may exacerbate other problems (Johnson, Moffat, \& Malchy, 2010; Ratschen, 2019). However, research shows that quitting smoking does not make a mental health condition worse and does not negatively impact on the effects of interventions designed to treat other addictions (Chengappa et al., 2001; Piper et al., 2013; Taylor et al., 2014). In fact, in our recent work with homeless smokers (funded by the NIHR PH ref: 17/44/29) we have shown that with the right support, smokers who are accessing homeless support services are able to reduce their cigarette consumption and make steps towards improving their health.

Managing nicotine craving and withdrawal

To be capable of quitting, smokers need to be able to manage their nicotine craving and withdrawal symptoms. Having access to adequate nicotine is therefore important. This can include using Nicotine Replacement Therapy (NRT) in the most optimal way (e.g. using a combination of products) or using higher nicotine concentrations. Empirical evidence shows that for heavier smokers, higher nicotine dosage in NRT is more effective for quitting (Lindson et al., 2019). This 
has also been demonstrated with nicotine patches (Przulj, Wehbe, McRobbie, \& Hajek, 2018); high dose patches (84mg) were well tolerated and associated with an impressive $82 \%$ CO- validated quit rate at 4 weeks.

Similarly, higher nicotine concentrations could be considered in EC. Currently the EU Tobacco Products Directive (TPD) stipulates a limit on nicotine e-liquid concentrations at $20 \mathrm{mg} / \mathrm{mL}$. With the UK's exit from the EU, the opportunity arises to reconsider this limit as recently endorsed by the House of Commons' Science and Technology Committee (House of Commons Science and Technology Committee, 2018). Raising the nicotine concentration limit in e-liquid is supported through a number of observations:

Many smokers have tried EC and reported that they were not sufficiently satisfying or strong enough compared to smoking and did not alleviate craving (e.g. ASH 2019;Brown, 2019).

In a qualitative exploration of vapers' perceived impacts and behavioural reactions to the TPD (Ward et al., under review)the $20 \mathrm{mg} / \mathrm{mL}$ limit on nicotine concentrations was also generally considered to be too low.

Some of the clearest evidence to support higher nicotine concentrations comes from a recent study by Foulds (2019), which demonstrates a clear advantage of higher nicotine concentration e-liquid (36mg/mL nicotine) for cessation (4.6 vs. $10.8 \%$ quit rate at 24 weeks with $8 \mathrm{vs}$. $36 \mathrm{mg} / \mathrm{mL}$ nicotine) in smokers with no plans to quit.

We have demonstrated across several studies with EC users, that compared with higher nicotine concentrations, use of lower nicotine concentrations is associated with more intensive puffing and a higher consumption of e-liquid (Dawkins et al., 2018; Dawkins, Kimber, Doig, Feyerabend, \& Corcoran, 2016)which increases exposure to any harmful compounds in the vapour (Kośmider, Kimber, Kurek, Corcoran, \& Dawkins, 2017).

\section{Support and training}

To tackle these issues, we suggest that targeted support and training is needed, intended for both health care professionals who support a wide range of smokers and smokers themselves. This can include support/training to quit alongside competing health and social needs, nicotine education and support to use products or to support people in accessingsupport \& services. Support also needs to be continued and repeated regularly. In our work, even after initial training around EC, staff and clients forgot essential information around how to use products effectively.

Supporting smokers through lapses is also pivotal to keeping people both interested and motivated. Evidence suggests that lapses are indeed inevitable; this should be accepted and support should continue at that point. The clearest evidence for the merit of continued and repetitive support comes from the US Lung Health Study in which 5,587 patients with mild COPD who were given repeated smoking cessation support every time they relapsed, showed an impressive 5 year quit rate of $37 \%$ (Anthonisen et al., 1994).

Opportunities

Accessibility and availability of a range of products, interventions and services 
A number of safer alternatives to smoking now exist, these include e-cigarettes $(E C)$, products that heat rather than burn tobacco (heated tobacco products) and snus, an oral nicotine delivery product that may or may not contain nicotine. These alternatives can help to displace smoking - for example, in Japan, cigarette sales have dropped by almost a third in the three years that heated tobacco products have been available (Stoklosa, Cahn, Liber, Nargis, \& Drope, 2019). In Sweden, snus has displaced smoking leading to less than $5 \%$ prevalence and the lowest lung cancer rates in the world ("Sweden - Global State of Tobacco Harm Reduction," n.d.). These products present a huge opportunity to reduce the harms from smoking and may appeal to resistant or heavily dependent smokers, especially those with a history of quitting. Unfortunately, the current status quo is that for the vast majority of smokers it is easier to obtain a pack of cigarettes than other safer products (including NRT or EC that are available in the UK) and poorer smokers and children from deprived areas are exposed to more tobacco sales points than those from wealthier areas (Shortt et al., 2015; Shortt, Tisch, Pearce, Richardson, \& Mitchell, 2016).

Maximising opportunities could also take the form of joined up or embedded services. NHS England has pledged to offer smoking cessation treatment to every hospital patient who smokers by 2024 but more could be done to augment quit attempts. Many of the most deprived and vulnerable already have to visit multiple settings/services, yet, if they do receive advice on smoking cessation, they are usually referred to yet another setting. Targeting smoking at a service or access point already being frequented (e.g. homeless centre, drug and alcohol service or GP setting) can increase opportunity to quit. Current work embedding smoking cessation services in other settings is underway in England; Dr Debbie Robson is leading a study exploring the impact of embedding smoking cessation into a substance misuse service in London, and in our own work, we have been offering EC at a point which homeless smokers are already accessing. In addition, in a recent observation study by our group offering free EC or NRT to smokers in a community based (non-High Street) pharmacy, all of the smokers were from the lowest SES groups, showing potential of community pharmacies to reach those from the routine and manual trades, at least when offering something new (Cox, Dawkins, Doshi, \& Cameron, 2019).

Price

Price needs to coincide with availability of support and products. Cost savings are important to smokers; for many, more important than personal health (Thirlway, 2019). However, with the increased number of smokers rolling their own or accessing cheap or illicit cigarettes, there is not always much of a cost saving when switching to reduced risk products such as EC or NRT (if not supported with a free prescription). While vaping is estimated to reduce monthly expenditure by £15 (Jackson et al., 2019), there is an initial start-up cost of around £25-30. Homeless smokers in our study reported only being able or willing to pay around £5-10 for a starter kit (Dawkins et al 2019). In the UK, benefits such as social support run at around $£ 71.80$ per week, so we can estimate that a high-quality e-cigarette starter kit is around $1 / 3$ of this income. This may be perceived as an unnecessary and potentially risky investment if the smoker i) likes smoking, ii) is unsure about the benefits of switching to vaping, iii) cannot easily access vaping equipment, and or iv) has no professional support in using the device. In trials and observational studies where smokers have been provided a free EC alongside behavioural support, quit rates have been promising (e.g., Hajek et al., 2019; Cox et al., 2019). 
Environmental Influences

Opportunities to smoke can be reduced and opportunities to vape, increased, through smoking and vaping policies. Although the UK has made considerable advancements in smoke-free policies, unfortunately many organisations are not considering vaping as distinct from smoking when creating policies and blanket bans are common. We suggest that by increasing the places where people can vape (considerably) whilst making it harder to find places to smoke can shift people towards vaping rather than smoking. In a study by Farsalinos and colleagues (Farsalinos, Romagna, \& Voudris, 2015)those who reported 'dual using' (smoking and vaping) reported vaping when smoking was banned, however environmental changes can help to tip the balance here in favour of using reduced risk nicotine products.

Motivation

Increasing opportunities and capabilities should increase motivation to quit but evidence suggests motivation can also be increased directly through a number of mechanisms.

Contingency Management

In a recent Cochrane review, incentivising smokers to quit by providing vouchers contingent on their abstinence has been shown to increase 6 month quit rates by 50\% (RR of quitting with incentives vs. control as 6 months $=1.49$ ) (Notley et al., 2019). These so-called contingency management approaches have traditionally been used on those sub-populations of smokers with other needs such as addicting drug users, homeless smokers or pregnant smokers.

Using the pack as a cessation tool

Cigarette or e-cigarette packs themselves can also be used to increase motivation. Plain packaging and graphic pictorial warnings can influence quit attempts (Noar et al., 2016)but may not work for those adopting the 'damage already done' mentality and we also know that smokers may ignore these messages or obscure them using pack covers (Maynard et al., 2014). Gain-framed messages on pack inserts focusing on the benefits of quitting and encouraging smoking cessation have been used successfully in Canada and have been shown to increase quit attempts (Thrasher et al. 2015, 2016). In relation to EC, our work has demonstrated that the current TPD pack message 'the product contains nicotine, a highly addictive substance' can reduce smokers' willingness to purchase and use an e-cigarette in a quit attempt (Cox, Frings, Ahmed, \& Dawkins, 2018). A reduced risk message, by contrast, e.g. 'Use of this product is much less harmful than smoking' can increase intentions to use in smokers without increasing usage intentions in non-smokers (Kimber, Frings, Cox, Albery, \& Dawkins, in press).

Another option is to use a loss-framed message on the cigarette itself (e.g. 'smoking kills' printed on cigarettes or rolling paper). Such 'dissuasive cigarettes' can increase negative health perceptions, reduce positive smoker image, decrease the desire to start smoking and increase desire to quit (Gallopel-Morvan, Droulers, \& Pantin-Sohier, 2019).

Developing confidence to quit via mastery of harm reduction 
Many smokers may lack the confidence or self-esteem to even attempt quitting - as illustrated in a quote from one smoker in our homeless work "l've never succeeded at anything - why should this be different?" Giving something up that has become so valuable to people can also be quite daunting. Even health professionals report feeling like they are being cruel in taking something away from people who have so little (Collins et al., 2018).

These are valid concerns which may be at least partly ameliorated through re-framing our messaging around quitting. For heavily dependent or more deprived smokers de-emphasising the 'quitting' or 'giving up' message and emphasising reducing may help to increase self-esteem as gains towards reductions are made. Moreover, evidence suggests that those smokers who are engaging in smoking reduction are more likely to go on to make a quit attempt (Beard \& West, 2012).

Recommendations

PH campaign (enhancing capabilities and motivation):

- Given the widespread misperceptions regarding nicotine and reduced risk projects namely e-cigarettes (EC), the first action we recommend isa large, widespread public health campaign toeducate about nicotine and harm reduction and to promote a range of cessation methods. This should include promotion of reduced risk products and the English Stop Smoking Services (SSS) which are known to be the most effective methods of quitting (Cancer Research UK \& Action on Smoking and Health, 2019; Hajek et al., 2019). To be maximally effective, information should be presented on prime time TV and endorsed by trusted sources such as the medical profession (e.g. Department of Health).

- Nevertheless, many medics, health professionals and support workers are also poorly informed about nicotine and reduced risk products yet these are the people that smokers turn to for advice and support. Targeted education and training for the medical profession should therefore be considered a priority-including education around nicotine and reduced risk nicotine containing products, how to support smokers to quit. Funding for such initiatives could come from the 'polluter pays' initiative.

Environment (enhancing opportunities):

Following education and training for health care professionals and medics, embed smoking cessation support from trained professionals within environments that are already being accessed by smokers including homeless centres, prisons, hospitals, mental health and addiction services and GP surgeries in order to reduce smoking related inequalities.

- Provide a clear and positive governmental steer on indoor vaping policiesin order to increase the number of places that people can vape. This can include permitting vaping in certain areas in in-patient mental health settings, drug and alcohol services, homeless centres, hospitals and prisons. This is a simple way of increasing opportunities to use reduced risk products at relatively little cost.

Giving smokers the nicotine they need and a range of products (enhancing capabilities)

- With the diverse current profile of smokers, a one size fits all approach will not work so a multi-pronged approach is 
needed including the availability of a wide range of approaches and products. This might include other safer noncombustible nicotine products such as EC, heated tobacco products, and snus which are easily accessible.

- Given the evidence reviewed regarding lack of satisfaction and craving relief from current products, we recommend allowing higher levels of nicotine in EC liquids in order to increase the number of smokers who successfully switch.

Pack messaging(enhancing motivation)

- Introduce mandatory pack inserts including smoking cessation information and signposting to the SSS

- Introduce dissuasive cigarettes through loss-framed messages on (smoking kills) cigarettes and cigarette papers

- Change the existing nicotine addiction TPD message on EC packs to a reduced risk message

\section{References}

Action on Smoking and Health (ASH). (2019). Use of e-cigarettes among young people in Great Britain. Action on Smoking and Health Website, (September), 1-14. Retrieved from https://ash.org.uk/wp-content/uploads/2019/06/ASHFactsheet-Youth-E-cigarette-Use-2019.pdf

Ahmed, Z., Preshaw, P. M., Bauld, L., \& Holliday, R. (2018). Dental professionals' opinions and knowledge of smoking cessation and electronic cigarettes: a cross-sectional survey in the north of England. British Dental Journal, 225(10), 947952. https://doi.org/10.1038/sj.bdj.2018.1026

Anthonisen, N. R., Connett, J. E., Kiley, J. P., Altose, M. D., Bailey, W. C., Buist, A. S., .. O'Hara, P. (1994). Effects of smoking intervention and the use of an inhaled anticholinergic bronchodilator on the rate of decline of FEV1. The Lung Health Study. JAMA, 272(19), 1497-1505. Retrieved from http://www.ncbi.nlm.nih.gov/pubmed/7966841

APPG. (2019). Delivering the vision of a "Smokingfree Generation."Retrieved from http://ash.org.uk/wpcontent/uploads/2019/03/2019-APPG-report.pdf

Brown, A. (2019). Responses to, and use of, a novel technology (e-cigarettes) by prisoners in Scottish prisons in the period immediately prior to going smoke-free. In Oral presentation delivered at the Society for Research on Nicotine and Tobacco Europe conference, Oslo, Oral session P3, 13/9/19.

Cancer Research UK, \& Action on Smoking and Health. (2019). A Changing Landscape for Stop Smoking Services and Tobacco Control in England. Retrieved from http://ash.org.uk/wp-content/uploads/2019/03/2019-LA-Survey-Report.pdf

Chaloupka, F. J., Yurekli, A., \& Fong, G. T. (2012). Tobacco taxes as a tobacco control strategy. Tobacco Control, 21(2), 172-180. https://doi.org/10.1136/tobaccocontrol-2011-050417

Chengappa, K. N., Kambhampati, R. K., Perkins, K., Nigam, R., Anderson, T., Brar, J. S., ... Levine, J. (2001). Bupropion sustained release as a smoking cessation treatment in remitted depressed patients maintained on treatment with selective 
serotonin reuptake inhibitor antidepressants. The Journal of Clinical Psychiatry, 62(7), 503-508.

https://doi.org/10.4088/jcp.v62n07a01

Cookson, C., Strang, J., Ratschen, E., Sutherland, G., Finch, E., \& McNeill, A. (2014). Smoking and its treatment in addiction services: Clients' and staff behaviour and attitudes. BMC Health Services Research, 14(1). https://doi.org/10.1186/1472-6963-14-304

Cox, S., Dawkins, L., Doshi, J., \& Cameron, J. (2019). Effects of e-cigarettes versus nicotine replacement therapy on short-term smoking abstinence when delivered at a community pharmacy. Addictive Behaviors Reports, 10, 100202. https://doi.org/10.1016/j.abrep.2019.100202

Cox, S., Frings, D., Ahmed, R., \& Dawkins, L. (2018). Messages matter: The Tobacco Products Directive nicotine addiction health warning versus an alternative relative risk message on smokers' willingness to use and purchase an electronic cigarette. Addictive Behaviors Reports, 8(August), 136-139. https://doi.org/10.1016/j.abrep.2018.09.006

Dawkins, L. E., Cox, S., Goniewicz, M. L., McRobbie, H., Kimber, C. F., Doig, M., \& Kosmider, L. (2018). 'Real-world' compensatory behaviour with low nicotine concentration e-liquid: subjective effects and nicotine, acrolein and formaldehyde exposure. Addiction. https://doi.org/DOI:10.1111/add.14271

Dawkins, L. E., Kimber, C. F., Doig, M., Feyerabend, C., \& Corcoran, O. (2016). Self-titration by experienced e-cigarette users: blood nicotine delivery and subjective effects. Psychopharmacology, 233(15-16), 2933-2941.

https://doi.org/10.1007/s00213-016-4338-2

Farsalinos, K. E., Romagna, G., \& Voudris, V. (2015). Factors associated with dual use of tobacco and electronic cigarettes: A case control study. International Journal of Drug Policy, 26(0), 595-600.

https://doi.org/http://dx.doi.org/10.1016/j.drugpo.2015.01.006

Fidler, J. A., Shahab, L., West, O., Jarvis, M. J., McEwen, A., Stapleton, J. A., ... West, R. (2011). "The smoking toolkit study": A national study of smoking and smoking cessation in England. BMC Public Health, 11(479). https://doi.org/10.1186/1471-2458-11-479

Foulds, J. (2019). Effects of electronic cigarettes on smoking cessation in smokers with no plans to quit: a randomised controlled trial. In Oral presentation delivered at the Society for Research on Nicotine and Tobacco Europe conference, Oslo, oral session 11, 14/9/19.

Gallopel-Morvan, K., Droulers, O., \& Pantin-Sohier, G. (2019). Dissuasive cigarettes: which cues are the most effective at deterring young people from smoking? Public Health, 174, 22-30. https://doi.org/10.1016/J.PUHE.2019.05.034

Garner, L., \& Ratschen, E. (2013). Tobacco smoking, associated risk behaviours, and experience with quitting: A qualitative study with homeless smokers addicted to drugs and alcohol. BMC Public Health, 13(1), 951.

https://doi.org/10.1186/1471-2458-13-951

Hajek, P., Phillips-Waller, A., Przulj, D., Pesola, F., Myers Smith, K., Bisal, N., ... McRobbie, H. J. (2019). A Randomized 
Trial of E-Cigarettes versus Nicotine-Replacement Therapy. New England Journal of Medicine, NEJMoa1808779. https://doi.org/10.1056/NEJMoa1808779

Hiscock, R., Dobbie, F., \& Bauld, L. (2015). Smoking cessation and socioeconomic status: An update of existing evidence from a national evaluation of english stop smoking services. BioMed Research International, 2015, 274056. https://doi.org/10.1155/2015/274056

House of Commons Science and Technology Committee. (2018). E-cigarettes Seventh Report of Session 2017-19 HC 505. Retrieved from https://publications.parliament.uk/pa/cm201719/cmselect/cmsctech/505/505.pdf

Jackson, S. E., Shahab, L., West, R., \& Brown, J. (2018). Roll-your-own cigarette use and smoking cessation behaviour: A cross-sectional population study in England. BMJ Open, 8(12), 1-10. https://doi.org/10.1136/bmjopen-2018-025370

Johnson, J. L., Moffat, B. M., \& Malchy, L. A. (2010). In the shadow of a new smoke free policy: A discourse analysis of health care providers' engagement in tobacco control in community mental health. International Journal of Mental Health Systems, 4, 23. https://doi.org/10.1186/1752-4458-4-23

Kimber, C., Frings, D., Cox, S., Albery, I., \& Dawkins, L. (n.d.). Communicating the Relative Health Risks of E-Cigarettes: An online experimental study exploring the Effects of a Comparative Health Message versus the EU Nicotine Addiction Warnings on Smokers' and Non-Smokers' Risk Perceptions and Behavioural Intentions. Addictive Behaviors.

Kock, L., Shahab, L., West, R., \& Brown, J. (2019). E-cigarette use in England 2014-17 as a function of socio-economic profile. Addiction, 114(2), 294-303. https://doi.org/10.1111/add.14446

Kośmider, L., Kimber, C. F., Kurek, J., Corcoran, O., \& Dawkins, L. E. (2017). Compensatory Puffing With Lower Nicotine Concentration E-liquids Increases Carbonyl Exposure in E-cigarette Aerosols. Nicotine \& Tobacco Research, 1-6.

https://doi.org/10.1093/ntr/ntx162

Lindson, N., Chepkin, S. C., Ye, W., Fanshawe, T. R., Bullen, C., \& Hartmann-Boyce, J. (2019). Different doses, durations and modes of delivery of nicotine replacement therapy for smoking cessation. Cochrane Database of Systematic Reviews, (4). https://doi.org/10.1002/14651858.CD013308

Maynard, O. M., Attwood, A., O’Brien, L., Brooks, S., Hedge, C., Leonards, U., \& Munafò, M. R. (2014). Avoidance of cigarette pack health warnings among regular cigarette smokers. Drug and Alcohol Dependence, 136(1), 170-174. https://doi.org/10.1016/j.drugalcdep.2014.01.001

McNeill, A., Brose, L. S., Calder, R., Bauld, L., \& Robson, D. (2018). Evidence review of e-cigarettes and heated tobacco products 2018 A report commissioned by Public Health England. Retrieved from https://www.gov.uk/government/uploads/system/uploads/attachment_data/file/679262/Evidence_review_of_ecigarettes_and_heated_tobacco_products_2018.pdf

Michie, S., van Stralen, M. M., \& West, R. (2011). The behaviour change wheel: a new method for characterising and 
designing behaviour change interventions. Implementation Science : IS, 6, 42. https://doi.org/10.1186/1748-5908-6-42 Noar, S. M., Francis, D. B., Bridges, C., Sontag, J. M., Ribisl, K. M., \& Brewer, N. T. (2016). The impact of strengthening cigarette pack warnings: Systematic review of longitudinal observational studies. Social Science and Medicine. NIH Public Access. https://doi.org/10.1016/j.socscimed.2016.06.011

Notley, C., Gentry, S., Livingstone-Banks, J., Bauld, L., Perera, R., \& Hartmann-Boyce, J. (2019). Incentives for smoking cessation. Cochrane Database of Systematic Reviews, (7). https://doi.org/10.1002/14651858.CD004307.pub6

Piper, M. E., Rodock, M., Cook, J. W., Schlam, T. R., Fiore, M. C., \& Baker, T. B. (2013). Psychiatric diagnoses among quitters versus continuing smokers 3 years after their quit day. Drug and Alcohol Dependence, 128(1-2), 148-154. https://doi.org/10.1016/j.drugalcdep.2012.08.023

Przulj, D., Wehbe, L., McRobbie, H., \& Hajek, P. (2018). Progressive nicotine patch dosing prior to quitting smoking: Feasibility, safety, and effects during the pre-quit and post-quit periods. Addiction. https://doi.org/10.1111/add.14483

Ratschen, E. (2019). Smokefree mental health inpatient settings - a matter of debate? SUCHT, 65(1), 42-49. https://doi.org/10.1024/0939-5911/a000576

Ritter, C., Stöver, H., Levy, M., Etter, J. F., \& Elger, B. (2011). Smoking in prisons: The need for effective and acceptable interventions. Journal of Public Health Policy, 32(1), 32-45. https://doi.org/10.1057/jphp.2010.47

Royal College of Physicians, \& Group, T. A. (2016). Nicotine without smoke Tobacco harm reduction. Retrieved from https://www.rcplondon.ac.uk/projects/outputs/nicotine-without-smoke-tobacco-harm-reduction-0

Shortt, N. K., Tisch, C., Pearce, J., Mitchell, R., Richardson, E. A., Hill, S., \& Collin, J. (2015). A cross-sectional analysis of the relationship between tobacco and alcohol outlet density and neighbourhood deprivation. BMC Public Health, 15, 1014. https://doi.org/10.1186/s12889-015-2321-1

Shortt, N. K., Tisch, C., Pearce, J., Richardson, E. A., \& Mitchell, R. (2016). The density of tobacco retailers in home and school environments and relationship with adolescent smoking behaviours in Scotland. Tobacco Control,25(1), 75-82. https://doi.org/10.1136/tobaccocontrol-2013-051473

Soar, K., Dawkins, L., Robson, D., \& Cox, S. (n.d.). Smoking amongst adults experiencing homelessness: A systematic review of prevalence rates, interventions and the barriers and facilitators to quitting and staying quit.

Stoklosa, M., Cahn, Z., Liber, A., Nargis, N., \& Drope, J. (2019). Effect of IQOS introduction on cigarette sales: evidence of decline and replacement. Tobacco Control, tobaccocontrol-2019-054998. https://doi.org/10.1136/tobaccocontrol-2019054998

Sweden - Global State of Tobacco Harm Reduction. (n.d.). Retrieved October 12, 2019, from https://gsthr.org/countries/s/se

Taylor, G., McNeill, A., Girling, A., Farley, A., Lindson-Hawley, N., \& Aveyard, P. (2014). Change in mental health after 
smoking cessation: systematic review and meta-analysis. BMJ (Clinical Research Ed.), 348, g1151.

https://doi.org/10.1136/bmj.g1151

Thirlway, F. (2019). Nicotine addiction as a moral problem: Barriers to e-cigarette use for smoking cessation in two working-class areas in Northern England. Social Science \& Medicine, 238(August), 112498.

https://doi.org/10.1016/j.socscimed.2019.112498

Villanti, A. C., Naud, S., West, J. C., Pearson, J. L., Wackowski, O. A., Niaura, R. S., ... Rath, J. M. (2019). Prevalence and correlates of nicotine and nicotine product perceptions in U.S. young adults, 2016. Addictive Behaviors,98, 106020. https://doi.org/10.1016/J.ADDBEH.2019.06.009

Ward, E., Anholt, C., Gentry, S., Dawkins, L., Holland, R., \& Notley, C. (n.d.). A qualitative exploration of vapers' perceived impacts, behavioural reactions, and future reflections of the EU Tobacco Products Directive (2017) as applied to electronic cigarettes.

West, R., Mohr, G., Proudfoot, H., \& Brown, J. (n.d.). Latest Statistics - Smoking In England. Retrieved October 10, 2019, from http://www.smokinginengland.info/latest-statistics/

Wilson, S., Partos, T., Mcneill, A., \& Brose, L. S. (2019). Harm perceptions of e-cigarettes and other nicotine products in a UK sample, 1-10. https://doi.org/10.1111/add.14502 